\title{
BLIND STUDENTS’ LEARNING OF PROBABILITY THROUGH THE USE OF A TACTILE MODEL
}

\author{
AIDA CARVALHO VITA \\ State University of Santa Cruz \\ Aida2009vita@gmail.com \\ VERÔNICA YUMI KATAOKA \\ State University of Santa Cruz \\ veronicayumi@,terra.com.br
}

\begin{abstract}
The objective of this paper is to discuss how blind students learn basic concepts of probability using the tactile model proposed by Vita (2012). Among the activities were part of the teaching sequence 'Jefferson's Random Walk', in which students built a tree diagram (using plastic trays, foam cards, and toys), and pictograms in $3 D$ (using the toys) to represent the possible ways in which Jefferson can visits his five friends and the expected frequencies of visits. The analysis of students' answers was based on the SOLO taxonomy, and developed from initial prestructural responses to final responses that were classified at the relational level. The study suggests adaptations of materials and teaching methods for helping blind students to learn about probability.
\end{abstract}

Keywords: Statistics education research; Teaching sequence; Basic probability concepts; SOLO taxonomy

\section{INTRODUCTION}

In the Brazilian context, the process of developing 'school for all' involves, among other actions, the inclusion of students with special educational needs (NEE, Necessidades Educacionais Especiais) in regular schools. According to the school census carried out in 2011 (Brasil, 2011), in the six-year period 2005-2011, the number of registrations of these students increased $113 \%$ in regular schools and decreased $48 \%$ in special schools. Despite this increase in the number of registrations, the effective inclusion of NEE students has represented a great challenge for regular schools (referred to simply as 'schools' from here on), which are still underprepared to ensure that these students have access to knowledge and educational opportunities (Brasil, 1998a). In order to adapt the school environment to respond to this growing demand, more specifically, to guide and assist the pedagogical work of the teacher, the Brazilian Government published documents outlining the national curricular parameters and adaptations (Brasil, 1998a) and the Projeto Escola Viva (Living School Project, Brasil, 2000). These documents suggest small examples of adjustments necessary to adapt artifacts and teaching methods for the effective participation of NEE students in learning activities.

There is still a shortage of research in Brazil on aspects of student inclusion, particularly on modifications that can contribute to teaching and learning mathematics for NEE students. We cite these examples that specifically involve blind students: Ferronato (2002), Fernandes (2004, 2008), Fernandes and Healy (2006), and Vita (2012). From a broader international perspective, we can also identify other studies: Gibson and Darron (1999) and Marson, Harrington and Wall (2012) in statistics, and Spindler (2006) in mathematics.

According to the International Classification of Diseases (WHO, 2010), the current definition of blindness applies to people who have 'irreversible' lack of perception of light or who do have perception of light but are nevertheless 'under $3 / 60$ ' in the better eye. The notation

Statistics Education Research Journal, 13(2), 148-163, http://iase-web.org/Publications.php? $p=$ SERJ C International Association for Statistical Education (IASE/ISI), November, 2014 
3/60 indicates that a person can see an object at 3 metres that could be seen by a normallysighted person at 60 metres.

For Ferronato (2002), teaching mathematics to such students is a difficult task, because these students need to have direct contact with, and actively manipulate, what is being taught. In his study, he developed an instrument called Multiplane to work with the concepts of geometry, trigonometry, statistics, and chart construction, among other topics. Fernandes (2004) developed an instrument adapted to the specific needs of these students, facilitating the teaching and learning process and enabling them to build up knowledge of the concept of symmetry.

In another study, Fernandes (2008) stated that the generalization and formalization of the mathematical concepts involved were motivated by the dialogue and gestures of the participants. The proposed instrument in this later study was used for the exploration of area, perimeter, and volume. Fernandes and Healy $(2006$, p.1) sought in their research to "understand how artifacts and signs (tools, symbols, words, gestures) influence the cognitive activity of learners without visual capacity at a normal level".

Spindler (2006) reported on his experience of tutoring university-level calculus to a blind student, indicating the strategies and challenges. Among the strategies, he cited careful verbal wording of formulas, simple manipulative materials and repetition. This author found that there are important differences but also many similarities between the learning of blind and sighted students; teachers provided with adequate resources can help such students learn successfully.

Gibson and Daron (1999) described how they developed cheap, low-tech teaching devices using cardboard and modeling clay for teaching a blind student in one of their statistics classes. The student touched these graphs and charts and explored them haptically to develop a high level of conceptual understanding.

Marson, Harrington and Wall (2012) reviewed various studies about teaching statistics and pointed out that the statistics educator has an ethical responsibility to create equal conditions, for example, by building artifacts that facilitate learning of statistical concepts by blind and visually impaired, as well as sighted students. This is particularly important as the understanding of many statistical concepts depends on visualization.

Back in the Brazilian context, Vita (2012) investigated the learning of basic concepts of probability by blind students, based on the curricular recommendations for mathematics at elementary school (Brasil, 1998b) and mathematics curriculum guidelines for high school (Brasil, 2006). The Brazilian documents suggest that it is up to the teachers to encourage students to perform experiments, observe events, represent data with tables and tree diagrams, and build the sample space in situations such as rolling dice or tossing coins. Vita (2012) also relied on the assessment of the material of the California Department of Education - The Braille Mathematics Standards (CDE, 2006), as regards the similarity of the probability topics that should be covered in basic school with blind students in that state.

Vita (2012) approached basic concepts of probability through tasks in the teaching sequence Jefferson's Random Walks (SE PAJ, Seqüencias de Ensino Passeios Aleatórios do Jefferson). The basic concepts involved were: sample space, events, probability of simple events, differences between a deterministic and a random experiment, estimating probabilities through relative frequency, calculating the theoretical probability from the 'tree of possibilities' or tree diagram, analysis of observed and expected patterns, and the construction of graphs.

The conception of probability adopted by Vita (2012) also fits with the definition of probabilistic literacy proposed by Gal (2005), which considers a person as literate in probability when she or he possesses basic skills, formal or informal, that allow her or him to read and interpret the probabilistic information present in their daily lives and, from there, to make decisions.

In this article our goal is to discuss aspects observed during the process of learning probability by blind students with the use of a tactile model, proposed by Vita (2012). It is important to mention that the results presented here are part of Vita's (2012) doctoral thesis in research in mathematics education, but she did not use the SOLO taxonomy for analyzing the results. 


\section{THE TACTILE MODEL}

SE PAJ's activities cover the basic concepts of probability from the perspective of the probabilistic literacy model proposed by Gal (2005). According to this author, this model is a set of two elements: cognitive knowledge and dispositional aspects. In this research, we focused only on the cognitive knowledge element, consisting of five blocks: big ideas; figuring probabilities; language; context; and critical questions.

Before the studies of Vita (2012), the SE PAJ was already being used by several researchers, including Cazorla and Santana (2006), Cazorla, Gusmão, and Kataoka (2011), Hernández, Kataoka, and Oliveira (2010) (who called it Monica's Random Walks, Passeios Aleatórios da Mônica, PAM), Cazorla, Kataoka and Nagamine (2010) and Ferreira (2011) (who called it Carlinha's Random Walks, Passeios Aleatórios da Carlinha, PAC). But in contrast to Vita's (2012) study, these surveys were developed with sighted students or teachers. We highlight that information so that we can present the adjustments proposed by Vita to facilitate the approach with blind students, which resulted in a tactile model (Figure 1).

In fact, Vita's tactile model was the result of a sequence of five prototypes, which in its final version consisted of recognition of the tactile instrument, the SE PAJ tasks, and a set of artifacts. These comprised the following items: a 3D board; seven plastic shapes with rectangular bases containing 54 square compartments arranged into nine rows and six columns, named a hive; 240 foam cards $2.5-\mathrm{cm}$ square with rough and soft textures; and 300 toys (60 each of dolls, whistles, yo-yos, rings, and hair bands); two caps and a cart.

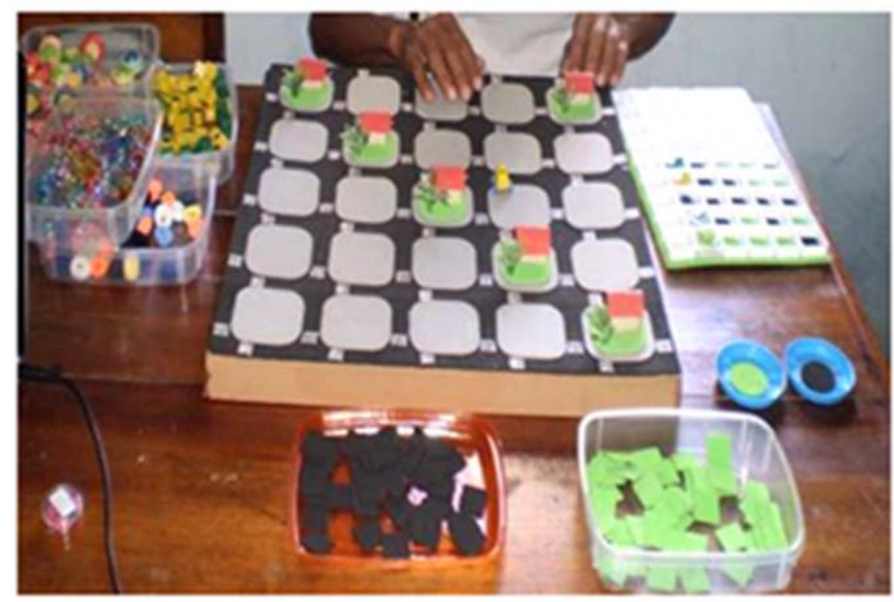

Figure 1. Final version of the tactile model (Vita, 2012, p. 108)

In the first task of the SE PAJ the following story was presented to the students:

Jefferson and his friends live in the same neighborhood represented by the 3D board. The distance from Jefferson's house to Luana's, Marcos's, Peter's, Orlando's, and Aida's is four blocks in every case. Jefferson used to visit his friends during the days of the week in a pre-established order: Monday, Luana; Tuesday, Marcos; Wednesday, Peter; Thursday, Orlando, and Friday, Aida. To make meetings more exciting, the group agreed to choose the friend being visited by Jefferson randomly. To do this, on the way out of his house and on every intersection, Jefferson would pick one of the two caps; if it's rough, he would walk a block north, if it's soft, one block to the east. Each play represents a block of the route with the obligatory stop at the crosswalk. Jefferson must draw the caps four times to get to the home of one of his friends.

In this story, for the SE PAJ a 3D board of $5 \times 5$ blocks and two caps with different textures representing direction (the movement of Jefferson on the board, rough $=$ north and soft $=$ east) are presented (Figure 2a). In the PAM and the CAP versions, a 2D poster and a coin are used; 
heads (C) indicated north and tails (X) indicated east (Figure 2b). We emphasize that the use of the caps for the draws allowed blind students a greater agility in reading and tactile handling.

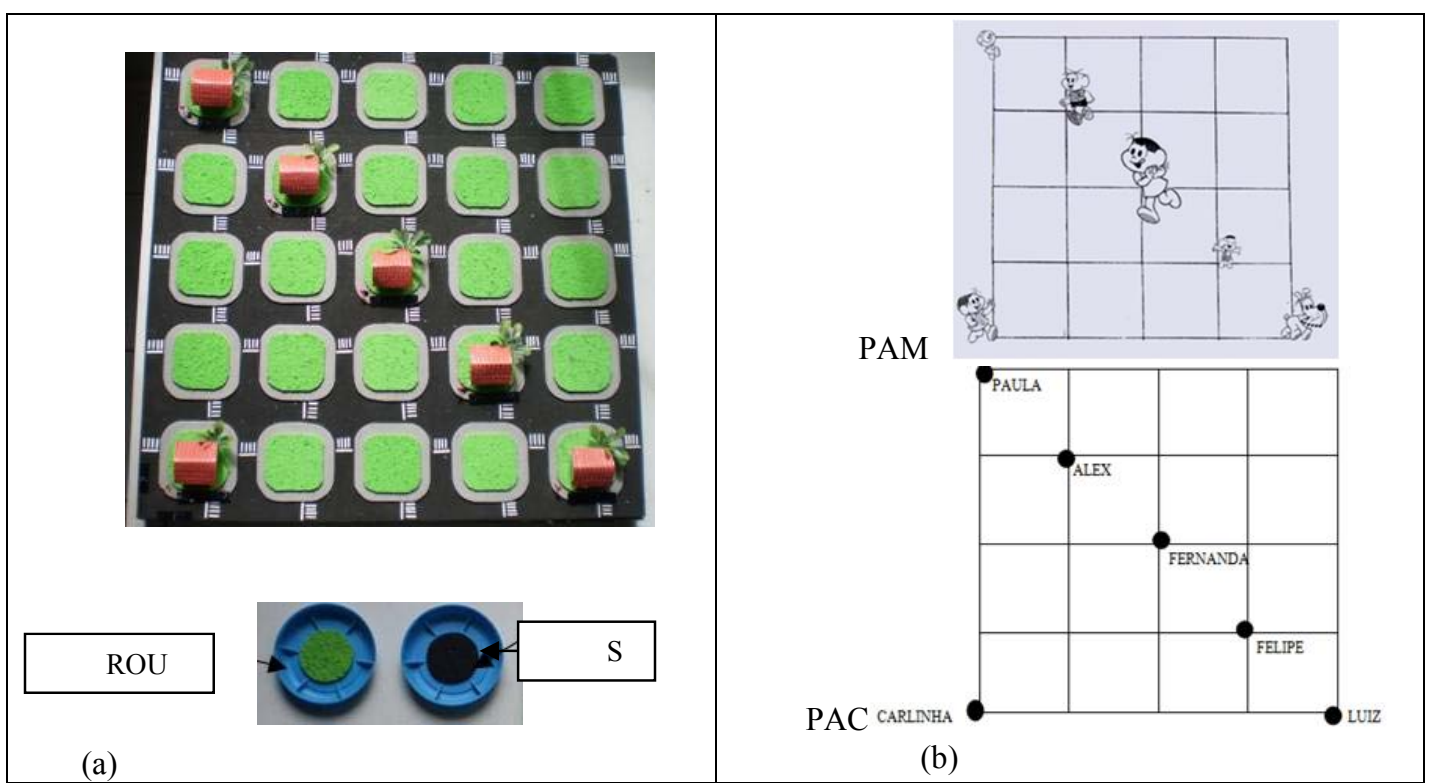

Figure 2. (a) $3 D$ board and caps for the SE PAJ (Vita, 2012, pp. 104, 182) and (b) $2 D$ poster for PAM (Cazorla \& Santana, 2006, p. 45) and PAC (Ferreira, 2011, p. 87)

Using the story, blind students were prompted, among other activities, to perform a random experiment by selecting a cap (before each selection, the caps were mixed) four times to determine the friend Jefferson visits, using a plastic cart to move around the board. To register the results of the 30 experiments carried out and to build a tree diagram for Jefferson's visits to his five friends, students used: the plastic shapes for recording (nine rows and six columns), which served as a reference guide, the foam cards with two different textures representing Jefferson's direction of movement on the board (rough $=$ north and soft $=$ east) and toys to represent each of the five friends (Figure 3). We use the term 'tree of possibilities' because we believe that this representation in the research of Vita (2012) has the same purpose as the usual tree diagram, which is the representation of all possible events of a given phenomenon.
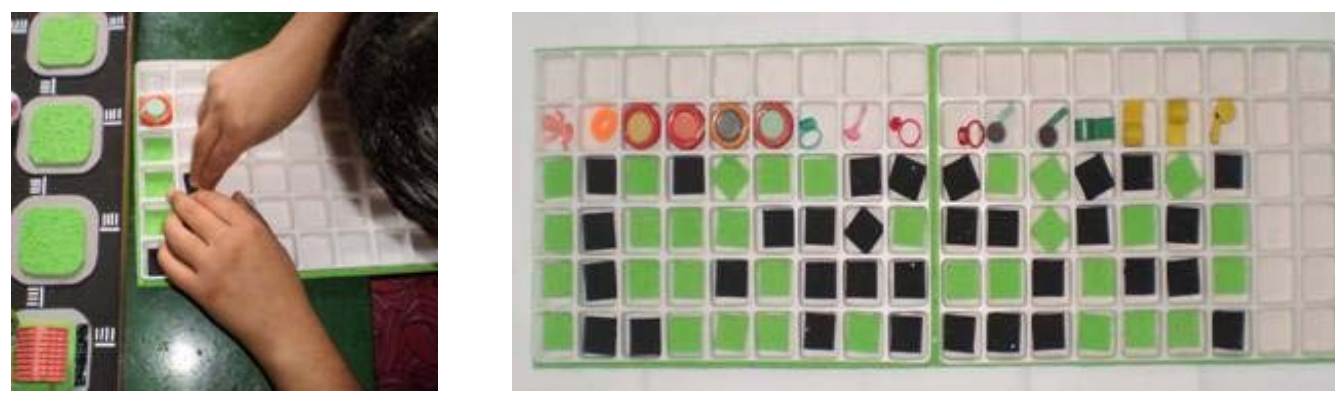

Figure 3. Artifact for recording the experiment and building the tree of possibilities. (Vita, 2012, pp. 193, 199)

In PAM and PAC, the student registers the results of the experiment in a table, later systematizing the results in another table, and then calculating relative frequencies. For constructing the tree diagram (or tree of possibilities), students use a grid with one example path already recorded, and they systematize the results in a table for the probability of visiting each of the friends. For constructing the bar graphs of relative frequencies and probabilities, 
students also use grids. These tables can be found in Ferreira (2011) and also in Ferreira, Kataoka, \& Karrer (2014).

Vita (2012) developed tactile modifications of these tables and grids for use by blind students. These and other adaptations were incorporated into the final prototype version.

\section{METHODOLOGY}

Vita's (2012) study for the development of the SE PAJ tasks was undertaken with three blind students. In Vita (2012), these students were referred to as S2, S3, and S4. At the time of the study, they were all over 18 years of age, and were enrolled in the second year of high school and also in special classes. It was a basic condition of their choice of subjects that they were enrolled in a regular public high school.

S2 was 32 years old, married with two children. He remembers he had low vision from childhood and became blind at the age of 21 due to a disease. He told us that he had lived and worked in the countryside for 25 years. Due to his work, his fingers thickened, hampering his tactile sensitivity, and making it difficult for him to read Braille. Even with this limitation, after some practice he became competent with the use of tactile models.

When S3 was 17, she began to suffer bad headaches. She says that her difficulty with eyesight began with the headaches. It would sometimes darken and sometimes brighten. When she was 19 years old, she gave up studying and finally, at the age of 22 she turned completely blind, and a large tumor was discovered behind her right ear. In addition to her blindness, she also experienced partial paralysis on the right side of her body. Even with this difficulty, S3 was able to familiarize herself rapidly with the elements on the board and the other artifacts.

S4 was 23 years old and said that she had turned blind at the age of five and learned to read in Braille alone, which enabled her to read this code with great ease. She could carry out calculations well with a soroban (or Japanese abacus) and she had a good memory for mental arithmetic.

Although the three students developed their blindness at different ages, there were no significant differences in the development of their activities and learning. Initially, all three were unfamiliar with the tactile model, but they soon became familiar with the board elements and other artifacts.

Before starting the SE PAJ tasks, tactile recognition activities were given to the students (called F1, set 1), aimed at familiarizing them with the instrument (model and tasks). Some of these tasks were geared specifically to investigate the usability of the model (flexibility, effectiveness and efficiency) and others suggested that the student try making moves on the board, as in the probability tasks. Usability-oriented tasks were inspired by design principles commonly used in tests employed by ergonomists to meet the standards of usability (Nielsen, 1993) of a system. In this article we will discuss the results of that set of tasks.

The SE PAJ tasks were divided into three sets, named F2, F3, and F4. The F2 contained ten tasks (from F2a to F2j) which were about contextualization, random experimentation and graphical representation (3D pictograms). F3 was composed of ten tasks (F3a to F3j) involving mathematical modeling (building the tree diagram) and graphical representation (3D pictograms).

We point out that the tasks $F 2 \mathrm{~h}-\mathrm{j}$ (to calculate and analyze the relative frequencies) and tasks F3i-j (to calculate the probabilities of Jefferson visiting each of his friends), as well as the three tasks of F4 (to compare relative frequencies and probabilities), were not carried out, since these students were unable to calculate division using decimal numbers. Vita tried to use the abacus, but the students did not know how to do division using this instrument either. The difficulties they had with these operations confirm the results of Tanti (2006) who showed that students displayed greater skills with mental arithmetic when the calculations are not long or complicated.

There were a total of 10 sessions with these students in meeting rooms with multifunctional resources to accomplish tasks F2 and F3, three meetings (totaling 7.5 hours) to work with S2, four meetings with S3 (totaling 8.5 hours), and three meetings with S4 (totaling 7 hours). S3 had a problem with her right arm and was reading the Braille information with her left hand, 
and so requiring a longer time to carry out the tasks. We also note that Cazorla, Kataoka, and Nagamine (2010) took six hours to carry out these same tests with sighted subjects.

The data were collected by filming the verbal instructions for the tasks by Vita and the oral replies of the students. The video recordings were later transcribed, and the students' gestures and actions when interacting with the tactile model were verified. In addition to the filming, students' answers to the tasks, including records on plastic forms such as 3D pictograms, were photographed.

For the analysis of results of some of the tasks in F2 and F3, we used the hierarchical model Structure of the Observed Learning Outcome (SOLO) Taxonomy proposed by Biggs and Collis (1991). This taxonomy is used to categorize student responses to a set of pre-established tasks, according to the structural complexity and the number of concepts required of them. According to Biggs and Collis (1991), this model makes the assumption that the student's cognitive understanding is not the same for every task, but depends on the content and context involved. Thus, the analysis does not focus on the cognitive structure of that individual, but rather on the particular understanding of a task, which differs from the constructivist model proposed by Piaget (Panizzon, Pegg, \& McGee, 2004).

Biggs and Collis (1991) defined five levels of response: prestructural, unistructural, multistructural, relational, and extended abstract. At the prestructural level, the student makes mistakes of fundamental understanding, with non-significant responses. At the unistructural level, the student presents several conclusions, that may be correct, but that are not consistent with each other, focusing on only one relevant aspect at a time. At the multistructural level, the student shows understanding, discusses the content consistently, has knowledge of a reasonable amount of content with various relevant responses, which are not coordinated and which may introduce some inconsistencies. The feature of the relational level is that the student integrates parts within a whole consistently, i.e., presents a conclusion able to link all relevant aspects, evidencing an overall coherence. However, the final conclusion may not serve for all contexts. Finally, the extended abstract is when the student generalizes beyond the information provided, showing a transition to a broader level of thought, but this level was not observed in the classification of responses to SE PAJ.

Using the proposed classification presented by Watson (2006) based on the SOLO taxonomy, we will analyze the responses of students to the tasks that required the construction of 3D pictograms corresponding to observed and expected frequencies.

Watson (2006) presented a problem to students in a context involving the number of books read by four children: namely, Anne 4, Danny 1, Lisa 6, and Terry 3. Cards with the faces of the children were used, as well as cards with a drawing of a book. The researcher handed out the cards and asked students to organize and represent this information. Younger students showed a pictographic representation Watson classified at the prestructural level (idiosyncratic response), because they only heaped the cards, separating the piles by child. The responses were classified at the unistructural level when students presented the cards in a scattered way, but with different groups for each child. At the multistructural level, students lined up the cards representing the books, allowing an easier visual comparison of the number of books read by each child. Finally, constructions in which students lined up the cards representing the books in accordance with the children in ascending order, using a reference guide, were categorized at the relational level.

\section{RESULTS}

At the first meeting, before the F2 and F3 tasks were presented, students were encouraged to express their initial conceptions of likelihood; in order to do so, Vita ('the researcher') summarized the part of the story where Jefferson had to pick one of the caps four times and check the friend visited, and she asked: "What are the chances of Jefferson reaching the home of each of the friends?"

When S2 didn't answer and just stared at the table, the researcher asked if he knew what probability was, and he answered: "I don't. Probability is a word ... that is possible?" (Vita, 2012, p. 187). Investigating the significance of words, the researcher questioned if she could 
replace the word 'probability' with 'chance'. S2 replied that she could change it. According to the researcher, by relating 'probability' to the words 'possible' and 'chance'. the student demonstrated knowledge of this mathematical concept, although he didn't know how to determine that in this specific context.

According to Santos (2010), for sighted students of the seventh grade of Elementary School, probabilistic terms express the chances of events related to them, and some of these terms express exact quantitative values, such as 'impossible', 'right', 'no doubt', and 'secure'. For Gal (2005), when using these terms, the individual already shows a certain level of probabilistic literacy. Watson (2006) states that the term 'chance' can be adopted as an approximation of probability to distinguish it from more intuitive and experimental aspects of theoretical probability based on sample spaces.

Students S3 and S4 reported not knowing the term probability, but S4 informed us that her mathematics teacher had talked about everything, but she did not remember anything about it. Once this preliminary research was over, the researcher initiated the implementation of tasks F2 and F3.

\subsection{TASKS F2}

In Task F2a, after reading the story, the following question was posed: "What is the difference between the old way and the new way of Jefferson visiting his friends?" According to the researcher, students didn't formally demonstrate the difference between a deterministic situation and a random experiment, but intuitively reported that in the old form of Jefferson visiting his friends Jefferson knew what friend he would visit, while the new way depended on chance. In their answers, students showed an understanding of the content and discussed it coherently, so they were classified at the multistructural level.

Unlike S3 and S4, S2 presented a contextualized situation when he said:

The draw may have led him to some place where there was no one at home. And the one who already knew what day he would be visited, he is all set to receive his friend. This creates a routine. The new way does not create a routine and can take someone by surprise, because the friend doesn't know which day he's going there (Vita, 2012, p. 189).

We believe that by using his experiences of daily visits- that is, his real-life experiences-this student contrasted a deterministic situation with a random experiment, demonstrating intuitive knowledge of these terms.

In Task F2b, the question was asked: What are the possible results of drawing the caps? We observed that S2, S3 and S4 identified that there were two possibilities (foam rough or soft), and thus students determined informally the events and the sample space of the experiment. These responses can be classified at the unistructural level, which would be the expected maximum level, since there are no other relevant aspects to be observed. That is, the only possibilities are: (1) that the student answered incorrectly or (2) expressed the sample space correctly.

In Task F2c, students had to answer the question: "What is the chance of having a rough cap? And a soft cap? Why?" As we had already identified in the preliminary investigation, we found that the students were unaware of the concept of probability (even though they used the term 'chance'), and in particular how to calculate it, since none of the students reported explicitly that the chance of drawing the cap with the rough or the soft foam is $50 \%$, or that both are equiprobable events, stating only that it would depend on the draw.

In the case of S2, he replied: "What do you mean? We have two caps, one rough and one soft? Either he goes to the north or to the east. Isn't it so?" (Vita, 2012, p. 190). In the face of that response, the researcher questioned what the chance was of going north or east, and S2 replied: "Precisely. I do not know! There's no chance, it's the same!" (p. 190). Despite his statement, it appears that S2 understood intuitively that the chances were equal. S3's response was: "It depends on the draw. It comes out rough or soft. The probability, I don't know. It is the possibility that depends on what comes out" (p. 190). S4 replied: "The possibility of the draw will depend on when you lift the cap. Rough or soft. This thing of probability, I don't know about it" (p. 190). 
In their explanations, the students only replaced the terms rough for north and soft for east, privileging the concrete situation from the artifacts of the model, to the detriment of the mathematical concept. Therefore, their answers may be classified as the prestructural level, as students have committed errors of understanding with non-significant justifications.

In Task F2d, students had to answer the following question: "Do all friends have the same chance of being visited? Yes or no and why?" S2, S3 and S4 claimed that the chance of Jefferson visiting each of his friends is not the same without formally justifying their answers, and so they can be classified as the unistructural level, since they are correct, but do not present a coherent discussion of the content. Similar results were found in studies by Cazorla, Gusmão, and Kataoka (2012) and Hernández, Kataoka, and Oliveira (2010), who claim that these responses could be based on theoretical probability or beliefs, but that at the moment of the experiment they were still unpredictable.

It is worth pointing out that S2, S3 and S4 did not show the strong awareness of equiprobable reasoning found by Cazorla and Santana (2006). For Vita (2012), with the tactile recognition of the model before the implementation of the tasks of the SE PAJ, students identified several paths to reach a particular friend, which may have influenced their intuitive concepts. Starting from this point of view, the researcher concluded that these tactile recognition tasks can be understood as an initial exploration of basic concepts of probability). She justified her statement by noting that, according to Gal (2005), familiar situations can lead students to understand intuitively the abstract nature of these topics. In this context, Vita (2012) states that the model also contributed to the learning of basic probability by these students.

On Task F2e, students were requested to perform a random experiment 30 times: a) to make the four choices sequentially; b) to select the cards; c) following the sequence, to record the choices on the plastic form; d) to move the cart on the board; e) to check off the friend visited; f) to receive the toy and record it also in the plastic form. This proposal is similar to the sequence of procedures carried out by Cazorla and Santana (2006) and Cazorla, Kataoka, and Nagamine (2010) with sighted subjects.

Overall, the researcher found that students undertook the 30 simulations satisfactorily and recorded them properly on the plastic form, and they quickly corrected the one or two errors that occurred during the records or moves on the board. According to Vita (2012), the students showed an increasing autonomy in their tactile movements on the board and in the use of the artifacts of the model. The record of S2's exploration can be seen in Figure 4.

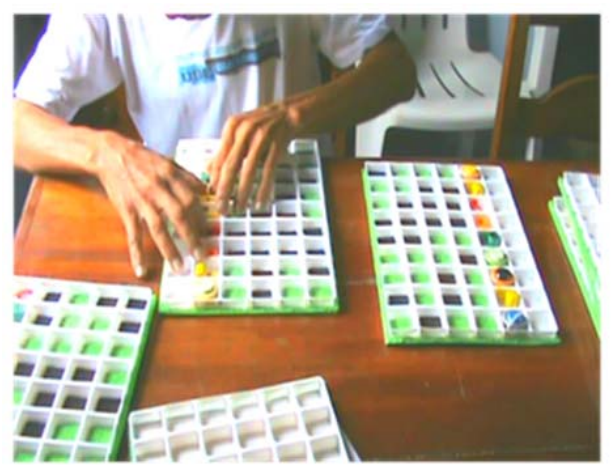

Figure 4. Record of the F2e Task by S2 (Vita, 2012, p. 194)

On Task F2f, students had to organize the results of their experiments in a graph, initially in whatever way they knew. Vita (2012) detected that they did not know how to create graphs, because they had always been given pre-constructed graphs, and could neither read nor interpret the information contained in the graphs. Similar results were found by Ferronato (2002).

We observe in the graph initially developed by S2 (Figure 5) that the toys (representing friends visited) were arranged in line, with a space separating each type of toy, as the examples 
of the yo-yo and the whistles show. According to Watson's (2006) definitions, we classify this chart as multistructural. This is because S2 lined up the toys, representing the visits to each of Jefferson's friends, which enabled him to make a tactile comparison of the number of toys of each type.

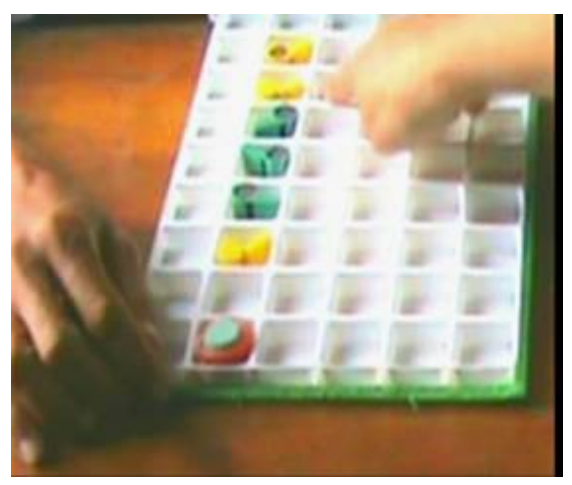

Figure 5. First graph constructed by S2 for F2f(Vita, 2012, p. 194)

When handling the graph, S2 had great difficulty in responding to the researcher's question about how many times each friend was visited. The researcher then suggested that the student use a column to represent each friend visited, and to put the 30 toys corresponding to the visits in the same order of placement as the houses on the board's diagonal. With this suggestion, the student separated each type of toy on the table, and then put them in the plastic form, starting the first column from left to right, and so building its 3D pictogram. Vita (2012) notes that during this, S2 constantly passed the fingers of both hands over the external edges of the shape (Figure 6) as a reference guide.

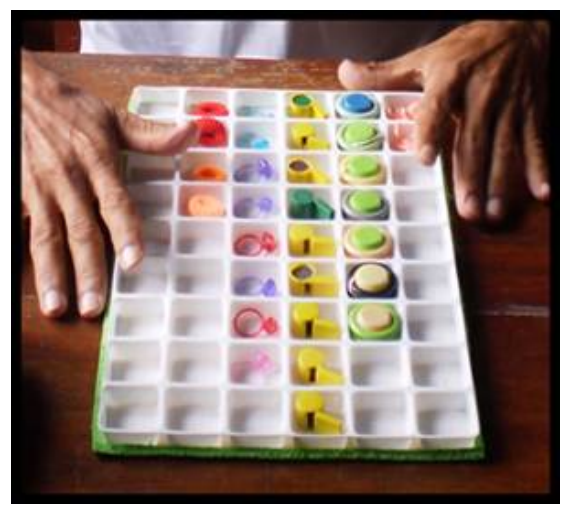

Figure 6. Pictogram constructed by S2 for F2f (Vita, 2012, p. 195)

This assistance by the researcher led S2 to build a 3D pictogram that could be classified at the relational level according to Watson (2006).

In the execution of this task, S3 stated that she did not know how to build the graph because she was never taught to do so at school. The researcher then presented her with a 3D pictogram from a fictional experiment for her tactile reading and $\mathrm{S} 3$ used that example to organize the result of her experiment as shown in Figure 7. 


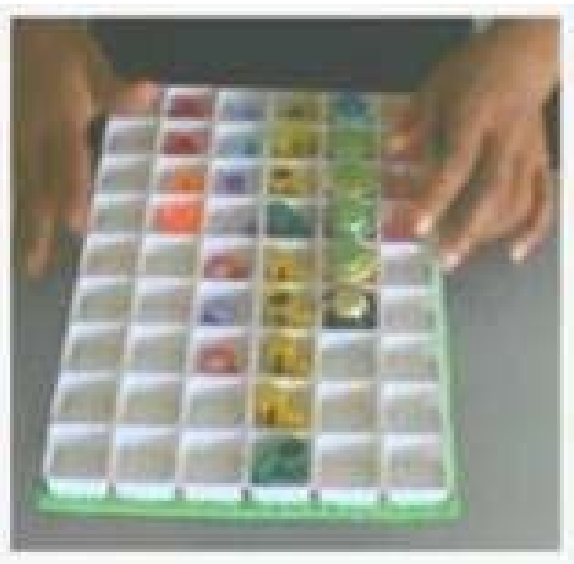

Figure 7. Pictogram constructed by S3 for F2f (Vita, 2012, p. 195)

Regarding the first record of S4, we can classify it in the unistructural level, according to Watson (2006), because she attempted to organize the visits in her experiment by putting the toys only on the sides of the plastic form, but separated according to the visited friends (Figure $8)$.

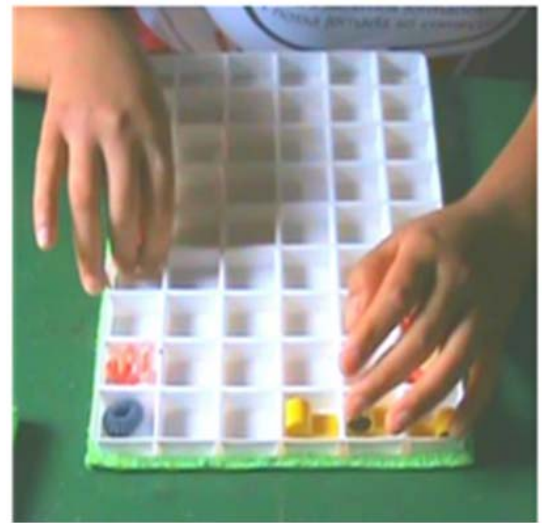

(a)

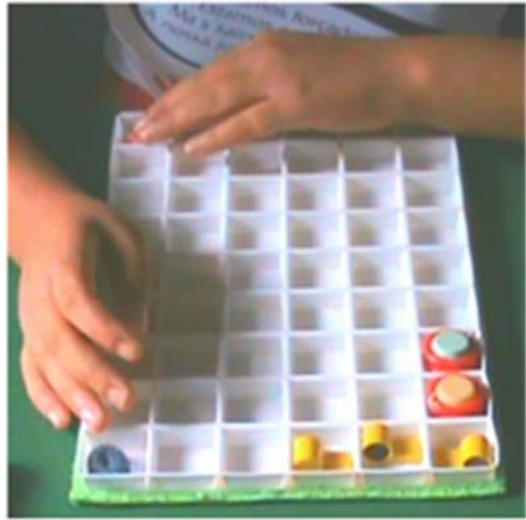

(b)

Figure 8. Image of S4 constructing her first graph for F2f(Vita, 2012, p. 196)

According to Vita (2012), S4 justified her organization of toys in the plastic form by saying that they were in the same position as the friends' houses on the board. By putting the hairband and the doll together, she reported that there were equal numbers of both toys, i.e., a single unit (Figure 8a). Then she separated them, stating that the homes of the friends corresponding to these toys were on the edges of the board (Figure 8b). As with S2 and S3, only after assistance by the researcher was $\mathrm{S} 4$ able to build a pictogram that could be classified as the relational level (Watson, 2006).

Recall that in PAM and PAC, sighted students or teachers use square meshes for constructing the bar graphs of relative frequencies and probability (see Figure 6). On Task F2g, the question was again: "Do all friends have the same chance of being visited? Yes or no, and why?" Even after the construction of the pictograms, S2, S3, and S4 claimed that the chances of Jefferson visiting each of the friends were not the same, but did not give a formal justification. These responses can then be classified at the unistructural level, since they are correct, but do not present a coherent discussion of the content; that is, we noticed that the students could not verbalize what the chances were of visiting each of the friends, nor say which of the friends was the most visited. 
Vita (2012) noted that while they were carrying out the tasks, the three students would at times pat the objects. According to them, this procedure was also a strategy for gathering information about the objects through hearing, as well through touch.

\subsection{TASKS F3}

In Task F3a, the students were asked to determine through the construction of a 'tree of possibilities' the possible paths to visit each of the friends. During the execution of this task, the difficulty was deciding on the possible paths to visit Peter (the friend whose house is located in the center of the 3D board). For this, they should have represented it in the form of six permutations of two rough foam cards and two soft. Students identified four of the six paths and, after numerous attempts, affirmed that these four paths were the only possibilities. For the other friends, the students did find all possible paths, even showing at times the ability to overcome other difficulties such as making and undoing records, and going back and forth to the board to confirm the record in the form, among others. The responses of the students to this task can be classified at the multistructural level since students showed understanding, had several relevant responses, but showed some inconsistencies.

The researcher intervened to ensure that all the paths to the house of Peter were identified and registered. This intervention was necessary because this task result would be used in subsequent tasks. After this intervention, the three students each recorded in the plastic form all 16 possible paths, and indicated the friend visited using the toy (Figure 9).

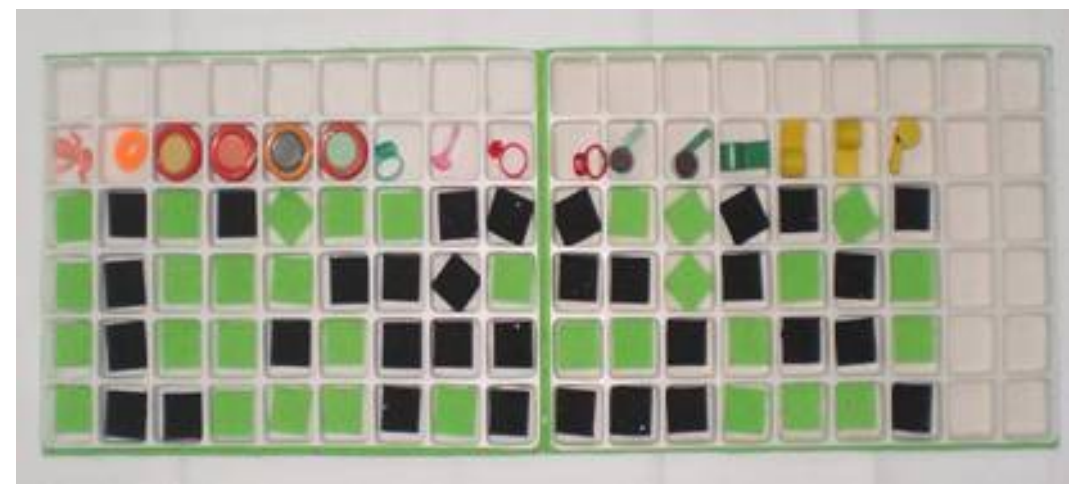

Figure 9. S2's record of all possible paths to visit friends (Vita, 2012, p. 199)

The difficulties facing these blind students were also observed with sighted students and teachers in previous studies. In Cazorla, Gusmão, and Kataoka (2011), two out of 28 mathematics teachers failed to identify all possible paths. Hernández, Kataoka, and Oliveira (2010), working with 91 students in the third year of high school, reported that $32 \%$ failed to find any relationship between the paths heading to each friend's house. In Ferreira (2011), the teacher-researcher had to intervene during the construction of the tree diagram in the case of three pairs of high school students. It is important to reflect that in the case of blind students, unlike sighted students and teachers, they did not have a grid nor one of the paths to serve as an example (see Figure 5). They had to start the construction of the tree without any prior ideas since they had not encountered it previously at school.

Using the record of the number of possible paths to visit each of the friends, still on Task F3a, students were requested to construct a pictogram to represent these results. The three students had no difficulty performing the task, since they had already experienced the construction of the pictogram of the frequencies observed in Task F2f. The graphs they constructed were classified at the relational level according to the definitions of Watson (2006).

We emphasize that S2 organized his pictogram with the 16 possible paths in a very particular way, always taking care to use the edges of the plastic form as a guide to facilitate his reading of the records. He had already shown some aptitude in the construction of the 
pictogram, recording and reading the information with skill. In this particular case, he organized the toys in columns and made an oral and tactile reading of the columns from top to bottom. Although reading columns in this way is not usual, he showed consistency in his graphical representation and justified it by stating that the position was not an influence, but it was important to start the placement of toys in each column in the same alignment (Figure 10). S3 and S4 positioned their pictograms columns horizontally, using the edges of the form as a reference.

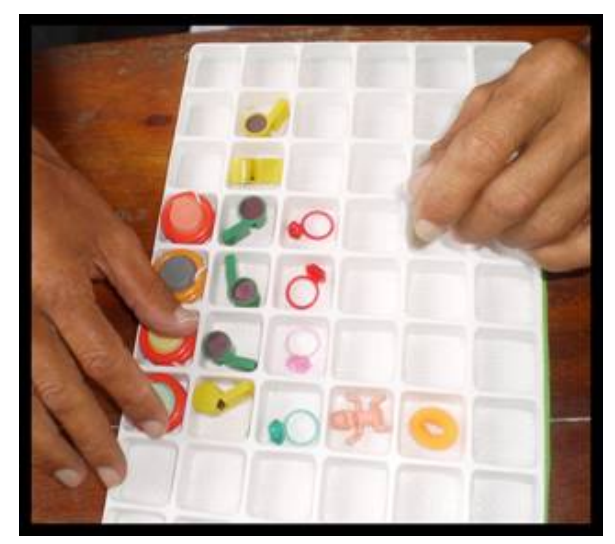

Figure 10. Pictogram made by S2 of possible paths (Vita, 2012, p. 199)

On Task F3b, the question was asked: "How many ways are there to visit Luana? What do they have in common?" The same question was repeated for Tasks F3c to F3f, changing the name of the friend to Marcos, Peter, Orlando and Aida.

Students responded quickly about the number of possible paths to reach the house of each one of the friends since they had already recorded the counts in Task F3a. However, they had difficulties in explaining what was common among the paths to get to the home of a particular friend, not recognizing the existence of patterns in the routes. Thus, their responses can be classified at the unistructural level, since they noted only one relevant aspect of the problem.

It is worth mentioning that S3, in order to find the paths to the home of Marcos, always moved the cart on the board; however, to inform us about the pattern or regularity present in these routes, she felt her way to where she had recorded three rough cards (representing three movements to the north), and a soft card (representing one movement to the east). Vita (2012) reported about S3's procedure that the student considered that Jefferson was regularly receiving a yo-yo when visiting Marcos' home, and only after an intervention was S3 able to identify that she needed to go three times to the north and once to the east.

In the context of this task, we observe that even though S3 had not initially cited the pattern to reach Marcos' house, her action in seeking an answer using the record in the form highlights the fact that the artifacts (3D board and plastic form) complement each other in order to carry out the tasks requested. In addition, from the records and the reading of them (Tasks F3a to F3f), students demonstrated that they had understood and appropriated the information.

On task F3g, students were asked again: "Do all friends have the same chance of being visited? Why?" This time, according to Vita (2012), S2, S3 and S4 all responded that the friends did not have the same chance and justified their answers based on the number of possible paths to each of the friends' houses. Students stated that Peter (at the center of the board) had more chance of being visited and Aida and Luana (houses at the corners of the board) had fewest opportunities to be visited. In addition, Orlando and Marcos had more chances than Aida and Luana, but fewer than Peter. These results indicate that students had obtained the expected answers to this task. Therefore, we consider that the task was performed in a satisfactory manner, and that the answers can be classified at the relational level. From these results, we can say that the plastic form, the cards and the toys were appropriate mediator instruments between blind students and the concepts involved in these tasks. 


\section{FINAL CONSIDERATIONS}

We realize the evaluation of learning of basic concepts of probability by blind students should also take into consideration the evaluation of the Vita's (2012) tactile model, because of the curricular adaptations required in order to make it possible for these students to learn these mathematical concepts. In this context, our first point is that the curricular adaptations to which we refer are adjustments in the tasks and the artifacts of the tactile model, the temporality of the implementation of the tasks, and the educational method.

With regard to the adjustments in the tasks, it is important to note that the tasks in SE PAJ have already been tested and evaluated with sighted students and teachers through the use of PAM and CAP, and so have been validated by several researchers (Cazorla \& Santana, 2006; Cazorla, Gusmão, \& Kataoka, 2011; Cazorla, Kataoka, \& Nagamine, 2010; Ferreira, 2011; Hernandez, Kataoka, \& Oliveira, 2010). To assist these subjects in their learning of basic probability, the tasks had to be adjusted at various times to meet the physical demands of blind students. For example, the tree diagram featured only the possible combinations (the last branches of the diagram) and the pictorial graphs that were built for them could be horizontal or vertical, and they used the sides of the plastic form as a reference guide. We point out that these adjustments in the tasks do not mean a change or deletion of the concepts involved, when compared with PAM and the CAP. Consistent with Fernandes (2004) and Vygotskian theory, blind students have the same potential as sighted students to understand notions related to mathematical concepts, since access is made possible by tools that can fulfill the function of the eye.

Regarding the adaptations of artifacts, several examples have already been cited in section 2, including comparing the materials used in PAJ with those used in PAM and PAC. Taking one of these examples, we highlight that changing the representation of a neighborhood from a $2 \mathrm{D}$ poster to a 3D board led to significant changes in the model, and also prioritized tactile recognition. It is worth remembering that students strategically created guide systems using the sides of the plastic form, putting the caps on the houses located on the board and this seems to have facilitated their interaction with basic probability, mediated by the tactile model. Reflecting on the actions of the subjects during the performance of the tasks, we can infer that the adaptations of the artifacts were important in assisting in the learning of basic probability by blind subjects, mediated by the tactile model.

The time taken by blind students to solve the tasks using experimentation with random choices must be considered, since the teacher has to respect the time that each student needs to carry out the tasks using the model. With regard to the adjustments in the teaching method, we realize that the initial difficulties of the students in solving the tasks, building the tree diagram, developing the random experiment, recording expected and observed frequencies, and using pictorial graphs, among others, were minimized with the researcher's intervention. In addition, her intervention is supported by the recommendations of the National Curriculum Parameters (Brasil, 1998a). These recommendations suggest that students should be aided by adaptations in teaching methods and didactical organization, as has been done by researchers (Ferreira, 2011; Tanti, 2006) who have played both teacher and researcher roles.

Finally, as stated in the methodology section, it was not possible to explore with these students how to calculate the relative frequency and the probability of Jefferson visiting each of his friends; and, by making comparisons between these results, to formalize the concept of probability. Therefore, we cannot address the second basic element ('figuring probabilities') in Gal's (2005) model of probabilistic literacy, which aimed to explore different ways to calculate probability.

On the other hand, we observed that the four other cognitive knowledge elements of this model ('big ideas', 'language', 'context', 'critical questions') were covered in the implementation of the remaining tasks. For example, the 'tree of possibilities' made students reflect, even if informally, on important ideas such as randomness.

Another example is related to the element of 'critical questions'. For example, the question of whether all friends had the same chance of being visited was asked at various points of SE 
PAJ, and we could understand the change in students' responses. Initially they could not justify their answers at all. After experimentation, they were still uncertain of how to make conjectures since the chances were different. But with the construction of the tree diagram, the reason for the different chances was evident to them, as well as an indication of the most-visited friend. This illustrates the students' interaction with the tasks, and a maturing of their answers - just what is proposed in the Gal (2005) model of probabilistic literacy. We emphasize also that the students' responses to this task moved from the prestructural level at the beginning of the investigation to the relational level with the tree diagram at the end.

Therefore, we believe that SE PAJ promoted important contributions to the development of these students' probabilistic literacy. Studies such as this one may help in the adaptation of materials and teaching methods for probability to better meet the individual requirements of blind students.

For future research, it would be of interest to study the tactile model with sighted and blind students and to observe their interaction with each other. In addition, it would be of interest to learn about teachers' opinions about using the tactile model to help sighted and blind students learn about probability, perhaps during teacher training. The results of such research may increase interaction between blind and sighted students and thus improve schools' inclusion of blind students.

\section{REFERENCES}

Biggs, J., \& Collis, K. (1991). Multimodal learning and the quality of intelligent behavior. In $\mathrm{H}$. Rowe (Ed.), Intelligence, reconceptualization and measurement (pp. 57-76). Mahwah, NJ: Lawrence Erlbaum Associates.

Brasil: Ministério da Educação (1998a). Secretaria de Educação Especial. Parâmetros Curriculares Nacionais: Adaptações curriculares [National Curriculum Parameters: Curricular adaptations]. Brasília: MEC/SEF.

Brasil: Ministério da Educação (1998b). Secretaria de Educação Especial. Parâmetros Curriculares Nacionais: Matemática [National Curriculum Parameters: Mathematics]. Brasília: MEC/SEF.

Brasil: Ministério da Educação (2000). Secretaria de Educação Especial. Projeto Escola Viva Garantindo o acesso e permanência de todos os estudantes na escola - Estudantes com necessidades educacionais especiais [Living School Project - Securing the access and retention of all school students - Students with special needs]. Adaptações curriculares de pequeno porte, v. 6 . Brasília: MEC/SEF.

Brasil: Ministério da Educação (2006). Secretaria de Educação Média e Tecnológica. Orientações Curriculares Nacionais para o Ensino Médio - Ciências da Natureza, Matemática e suas Tecnologias [National Curriculum Guidelines for Secondary Education - Natural Sciences, Mathematics and Technology]. Brasília: MEC/SEF.

Brasil: INEP (Instituto Nacional de Estudos e Pesquisas Educacionais Anísio Teixeira) (2011). Censo Escolar [School Census]. [Online: http://portal.inep.gov.br/basica-censo ]

California Department of Education (CDE) (2006). Braille Mathematics Standards. Sacramento, CA.

[Online: http://www.cde.ca.gov/sp/se/sr/documents/braillemathstand.pdf]

Cazorla, I. M., \& Santana, E. R. dos S. (2006). Tratamento da Informação para o Ensino Fundamental e Médio (1st. ed., v.1) [Treatment of Information for Elementary and Secondary Education]. Itabuna, Bahia, Brasil: Via Litterarum.

Cazorla, I. M., Gusmão, T. C., \& Kataoka, V. Y. (2011). Validação de uma sequência didática de probabilidade a partir da análise prática de professores do enfoque ontossemiótico [Validation of a didactic sequence for probability from practical analysis of teaching with an onto-semiotic focus]. Bolema, 24(39), 537-560.

Cazorla. I., Kataoka, V, Y., \& Nagamine, C. M. L. (2010). Os Passeios Aleatórios da Carlinha. Tutorial, AVALE-EB [Carlinha's Random Walks]. [Online: http://ambiente.educacao.ba.gov.br/conteudos/download/1622.pdf] 
Fernandes, S. H. A. A. (2004). Uma Análise Vygotskiana da Apropriação do Conceito de Simetria por Aprendizes sem Acuidade Visual [A Vygotskian Analysis of the Appropriation of the Concept of Symmetry by Learners without Visual Acuity]. Masters of Mathematics Education dissertation. Pontifícia Universidade Católica de São Paulo, São Paulo: PUC/SP.

Fernandes, S. H. A. A. (2008). Das Experiências Sensoriais aos Conhecimentos Matemáticos: Uma análise das práticas associadas ao ensino e aprendizagem de alunos cegos e com visão subnormal numa escola inclusiva [Sensory Experiences of Mathematical Knowledge: An analysis of the practices associated with the teaching and learning of blind and lowvision students in an inclusive school]. Doctoral thesis in Mathematics Education. Pontifícia Universidade Católica de São Paulo, São Paulo: PUC/SP.

Fernandes, S. H. A. A., \& Healy, L. (2006). Mãos que falam; mãos que vêem. O papel do sistema háptico no processo de objetificação do conhecimento matemático por alunos cegos [Hands that speak; hands that see. The role of the haptic system in the process of objectification of mathematical knowledge by blind students]. In Anais da VI Reunião de Didática da Matemática do Cone Sul, Águas de Lindóia. São Paulo: PUC São Paulo.

Ferronato, R. A. (2002). Construção de Instrumento de Inclusão no Ensino da Matemática [Building Instruments for the Inclusion of Students in Mathematics]. Master of Production Engineering dissertation. Universidade Federal de Santa Catarina, Florianópolis: UFSC.

Ferreira, R. S. (2011). Ensino de Probabilidade com o Uso do Programa Estatístico R numa Perspectiva Construcionista [Teaching Probability with the Use of the Statistical Program $R$ with a Constructionist Perspective]. Masters in Mathematics Education dissertation. Universidade Bandeirante de São Paulo, São Paulo.

Ferreira, R. S., Kataoka, V. Y., \& Karrer, M. (2014). Teaching probability with the support of the R statistical software. Statistics Education Research Journal, 13(2), 132-147. [Online: http://iase-web.org/documents/SERJ/SERJ13(2)_Ferreira.pdf]

Gal, I. (2005). Towards "probability literacy" for all citizens: building blocks and instructional dilemmas. In G. A. Jones (Ed.), Exploring probability in school: Challenges for teaching and learning (pp. 39-63). New York: Springer.

Gibson, W., \& Darron, C. (1999). Teaching statistics to a student who is blind. Teaching of Psychology, 26(2), 130-131.

Hernández T. H. M., Kataoka, V. Y., \& Oliveira, M. S. de (2010). Random walks in teaching probability at the high school. In C. Reading (Ed.), Proceedings of the 8th International Conference on Teaching Statistics - ICOTS8, Ljubljana, Slovenia.

[Online: http://iase-web.org/documents/papers/icots8/ICOTS8 2B1_HERNANDEZ.pdf]

Marson, S. M., Harrington, C., \& Wall, A. (2012). Teaching introduction to statistics to a blind student. Teaching Statistics, 35(1), 21-25.

Nielsen, J. (1993). Usability engineering. San Francisco: Morgan Kaufmann. Inc.

Panizzon, D., Pegg, J., \& McGee, S. (2004). Incorporating different assessment tasks to gauge student understandings of planetary processes. In P. L. Jeffery (Ed.), Proceedings of AARE International Education Research Conference (pp. 1-18). Melbourne: Australian Association for Research in Education. [Online: http://www.aare.edu.au/04pap/pan04654.pdf]

Santos, J. A. F. L. (2010). O Movimento do Pensamento Probabilístico Mediado pelo Processo de Comunicação com Alunos do $7^{\circ}$ Ano do Ensino Fundamental [The Development of Probabilistic Thought Mediated by the Process of Communication with Students in the 7th Year of Elementary School]. Masters of Education dissertation. Universidade São Francisco, São Paulo: USF/SP.

Spindler, R. (2006). Teaching mathematics to a student who is blind. Teaching Mathematics and its Applications, 25(3), 120-126.

Tanti, M. (2006). Teaching mathematics to a blind student: A case study. Masters in Education dissertation, University of Exeter, UK. [Online: http://people.exeter.ac.uk/PErnest/pome20/MariellaTantiTeachingMathematicstoaBlindStudent-ACaseStudy.pdf ]

Vita, A. (2012). Análise Instrumental de uma Maquete Tátil para a Aprendizagem de Probabilidade por Estudantes Cegos [Instrumental analysis of a tactile model for learning 
probability for blind students]. Doctoral thesis in Mathematics Education. Pontifícia Universidade Católica de São Paulo, São Paulo.

Watson, J. M. (2006). Statistical literacy at school: Growth and goals. London: Lawrence Erlbaum Associates.

World Health Organization (2010). Change the Definition of Blindness.

[Online: http://www.who.int/blindness/Change\%20the\%20Definition\%20of\%20Blindness.pdf ]

VERÔNICA YUMI KATAOKA

State University of Santa Cruz

Campus Soane Nazaré de Andrade, Módulo 03 - Pavilhão Jorge Amado

Rodovia Jorge Amado, Km 16, Bairro Salobrinho

CEP 45662-900, Ilhéus-Bahia-Brasil 